\title{
Clinical Applications of Ultrasound Biomicroscopy in Glaucoma
}

\author{
Saurabh Patwardhan, Shalini Mohan, Sujith Vengayil, Anand Aggarwal, Viney Gupta, Ramanjit Sihota \\ Glaucoma Service, Dr Rajendra Prasad Centre for Ophthalmic Sciences, New Delhi, India \\ e-mail:patwardhan.sourabh@gmail.com
}

\section{INTRODUCTION}

Ultrasound biomicroscopy (UBM) is a high resolution ultrasound technique developed by Pavlin, Sherar and Foster in Toronto in the late 1980s. UBM is a high-frequency (50 MHz) ultrasound technology using water bath that allows noninvasive in vivo imaging of structural details of the anterior ocular segment at near microscopic resolution. ${ }^{1-5}$ It provides exceptionally detailed two-dimensional gray-scale images of the various anterior segment structures and evaluates them both quantitatively and qualitatively.

\section{CLINICAL APPLICATIONS OF UBM}

Since its introduction it has been used in various clinical and experimental studies on glaucoma where it has been used for diagnostic purposes. Imaging with this technology has diverse applications in various forms of primary and secondary glaucomas.

\section{Examination of the Anterior Chamber Angle}

With the UBM, one can examine the angle structures in which iris, ciliary body, and scleral spur can be recognized easily. The scleral spur is the only constant landmark allowing one to interpret images and is the key for analyzing angle pathology. The scleral spur can be identified in the region where the radiopaque shadow of the sclera merges with the relatively radiolucent shadow of the cornea and is often visible as a change in the configuration when the inner border as the sclera merges into the cornea. ${ }^{6}$ Exact angle measurements can be made in degrees and the angle-opening distance and recess area documented.

\section{Biometry of the Anterior Segment}

With the UBM one can determine the corneal thickness, anterior chamber depth, posterior chamber depth, IOL thickness, iris thickness, ciliary body thickness, scleral thickness, etc. However, one cannot determine the lens thickness due to the reduced depth of penetration $(<5 \mathrm{~mm})$, thereby not allowing visualization of the posterior capsule of the lens when a 50 MHz probe is used. ${ }^{7}$ Sulcus to sulcus and angle to angle measurements can also be performed.

\section{Determining the Mechanism of Primary Glaucoma}

Ultrasound biomicroscopy is usually able to determine the mechanism of elevated intraocular pressure (angle-closure versus open-angle) by showing the relationship between the peripheral iris and trabecular meshwork. ${ }^{6,7}$

In addition, imaging of the anterior segment structures is possible even in eyes with corneal edema or corneal opacification that precludes gonioscopic assessment.

In open-angle glaucoma, UBM can be used to measure the anterior chamber angle in degrees, to assess the configuration of the peripheral iris, and to evaluate the iris insertion in relation to the trabecular meshwork. One can see if there is an anterior insertion of the iris or an anteriorly displaced ciliary body. In eyes with a narrow angle, UBM shows the extent of angleclosure, reveals the depth of the anterior and posterior chambers, and identifies pathologic processes pushing the lens and iris forward.

The authors performed UBM studies in the subtypes of primary angle-closure glaucoma and documented that eyes with primary angle-closure glaucoma have a thinner iris and shorter trabecular ciliary process distance in addition to a narrow angle. ${ }^{8}$ Acute primary angle-closure eyes were confirmed to have the narrowest angle recess. In eyes with primary angle-closure, older age and a shallower ACD appear to be important causes of increased forward bowing of the iris resulting in pupillary block. ${ }^{9}$ Thus, UBM is helpful in predicting the risk of developing angle-closure.

\section{To Determine Occludability of the Angle}

One can perform darkroom provocative testing with the UBM, to study the spontaneous occlusion of the angle under conditions of decreased illumination (Figs 1 and 2). This helps to identify "at risk" population which can then be subjected to a laser iridotomy. It is better than darkroom gonioscopy because 


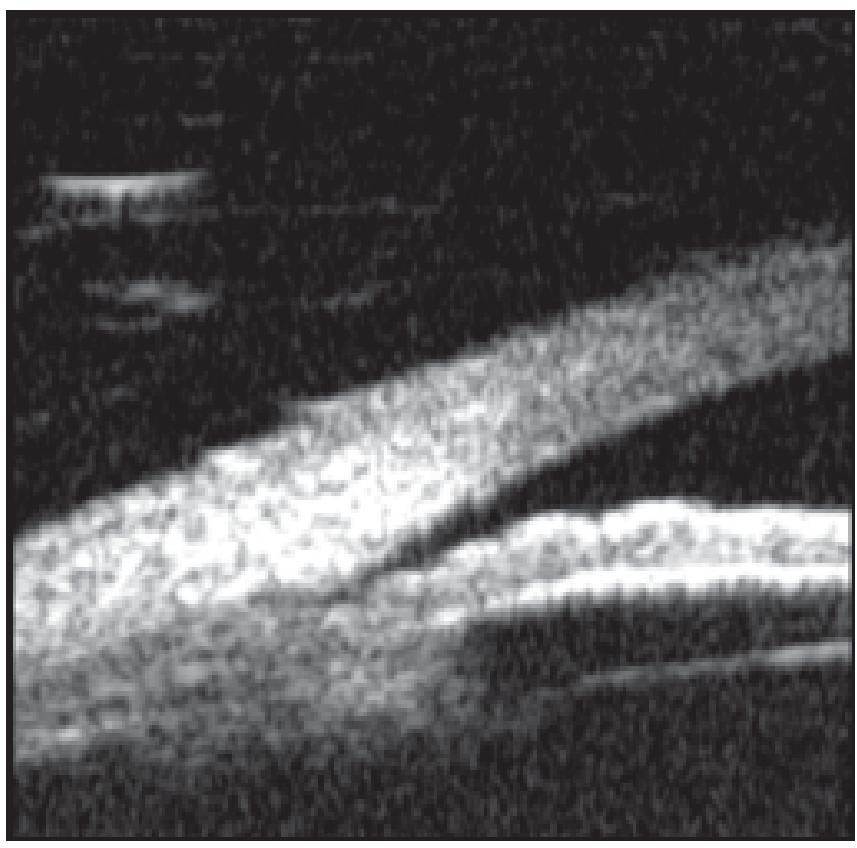

Fig. 1: Open-angle in bright illumination

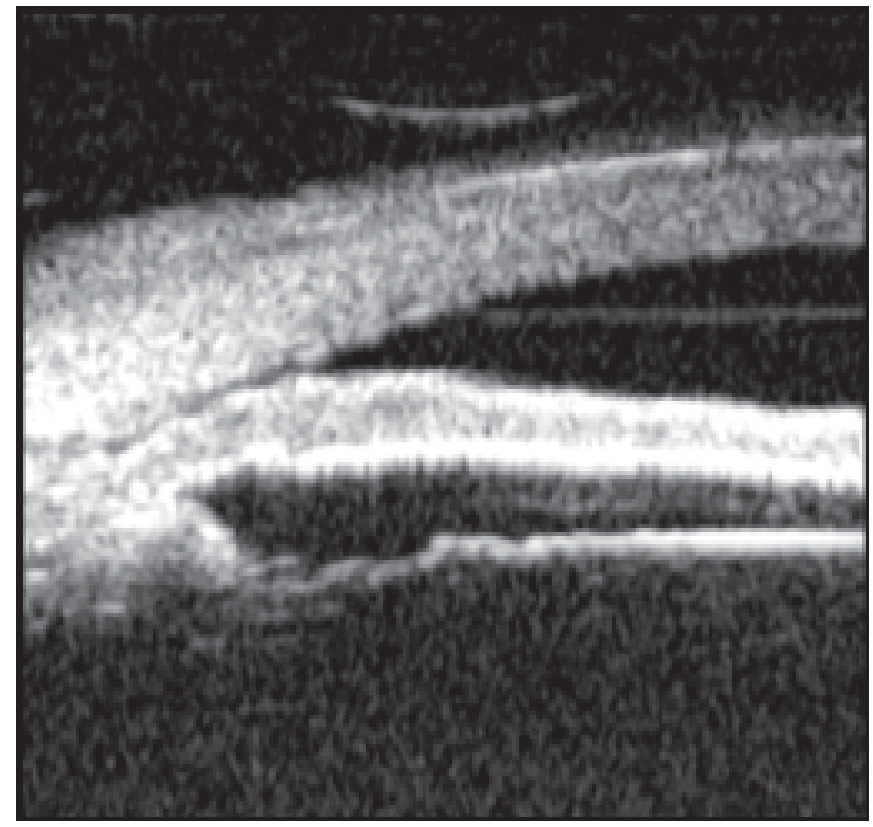

Fig. 2: Appositional angle-closure in dim illumination

the latter is time-consuming and standardization of slit-lamp illumination is difficult.

Wang $\mathrm{N}$ et al $^{10}$ compared the traditional darkroom provocative tests (gonioscopy and applanation tonometry) with UBM biometry. With the appositional angle-closure as a positive diagnostic criterion, the sensitivity of the traditional test and UBM darkroom test was 31.8 percent and 68.2 percent, respectively. The specificity of both methods was 100 percent. UBM darkroom provocative test therefore elevates the sensitivity and specificity of traditional darkroom test, and reduces the false-negative or -positive rate in screening PACG, which is helpful to its accurate diagnosis.

Sano $\mathrm{R}$ et al $^{11}$ suggested comparison of angle parameters in supine and prone positions can be another method to predict risk for angle-closure even in absence of positive prone provocation test (PPT). In this study, while the intraocular pressure was higher after PPT than before the test, every subject was evaluated as negative for PPT. Mean value of every parameter examined was lower in the prone position than in the supine position (AOD 250: 114 microns, vs 128 microns, AOD 500: 121 microns vs. 144 microns, TIA: 12.1 degrees vs 15.5 degrees, ACD: 1966 microns vs. 2002 microns), and the change in ACD was statistically significant. Thus the anterior chamber configuration of patients with narrow angle is changed in prone position and such a change can occur even in patients classified as negative for PPT. Ishikawa $\mathrm{H}$ et al ${ }^{12}$ added that the more posterior the iris insertion on the ciliary face, the less likely that the provocative test will be positive.

Indentation UBM gonioscopy is a new method for observing the angle and making a diagnosis of relative pupillary block, peripheral anterior synechiae, and plateau iris configuration by applying pressure on the eye cup. Advocated by Matsunaga K et al, ${ }^{13}$ this technique caused widening of all examined angles. The angle changes in eyes with relative pupillary block (RPB) were significantly greater than in eyes with peripheral anterior synechiae (PAS) or plateau iris configuration (PIC). It was concluded that indentation UBM gonioscopy is a very useful method for observing the angle and diagnosis of RPB, PAS, and PIC.

\section{Effect of the Valsalva Maneuver}

The authors performed an evaluation of the effect of the Valsalva maneuver on the anterior chamber configuration using the UBM. Significant elevation of the intraocular pressure, narrowing of the anterior chamber angle recess, thickening of the ciliary body and increase in the iris thickness was seen during the Valsalva maneuver. The study showed that the Valsalva maneuver which comes into play in many activities of daily living, may lead to angle-closure in eyes which are anatomically predisposed to primary angle-closure glaucoma ${ }^{14}$ (Figs 3 and 4).

UBM can be used as a dynamic differentiating method to compare the morphologic characters of the anterior chamber angle especially in eyes at risk of angle-closure. ${ }^{15}$ Different illuminations influence the UBM examination of the anterior chamber angle significantly, and the angle morphology should be checked under different illuminations if it seems to be closed.

\section{Congenital Glaucoma}

Wang $\mathrm{N}$ et al $^{16}$ used UBM to investigate the characteristics of congenital glaucoma. They found that UBM can show the 


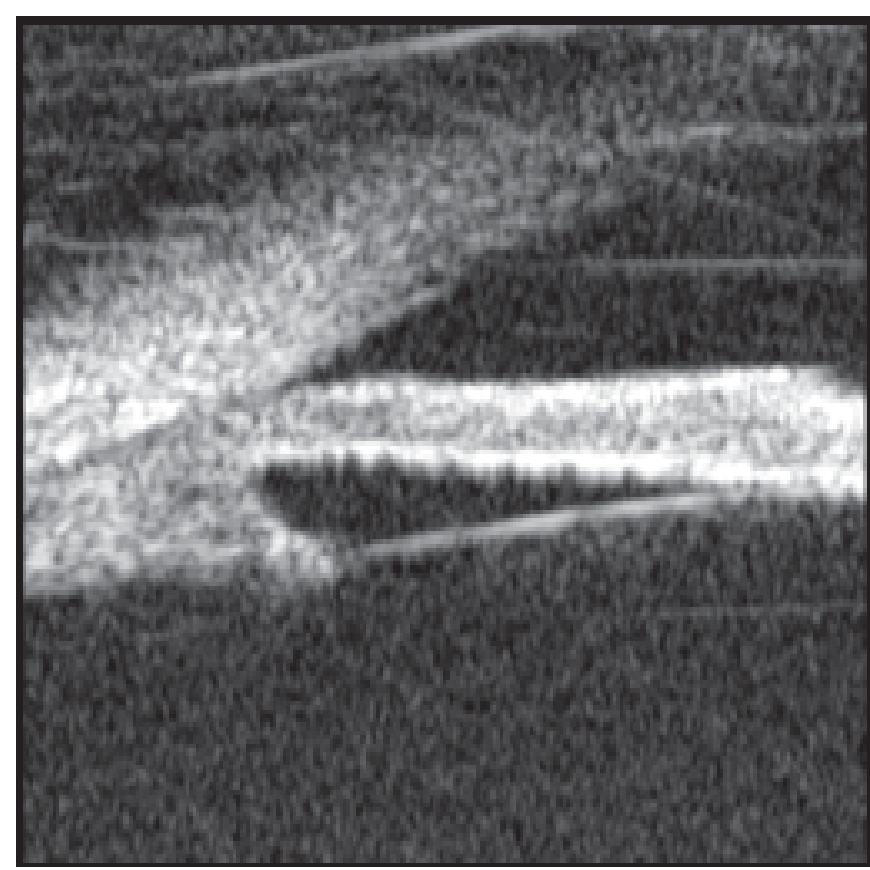

Fig. 3: Before Valsalva maneuver (wide open-angle)

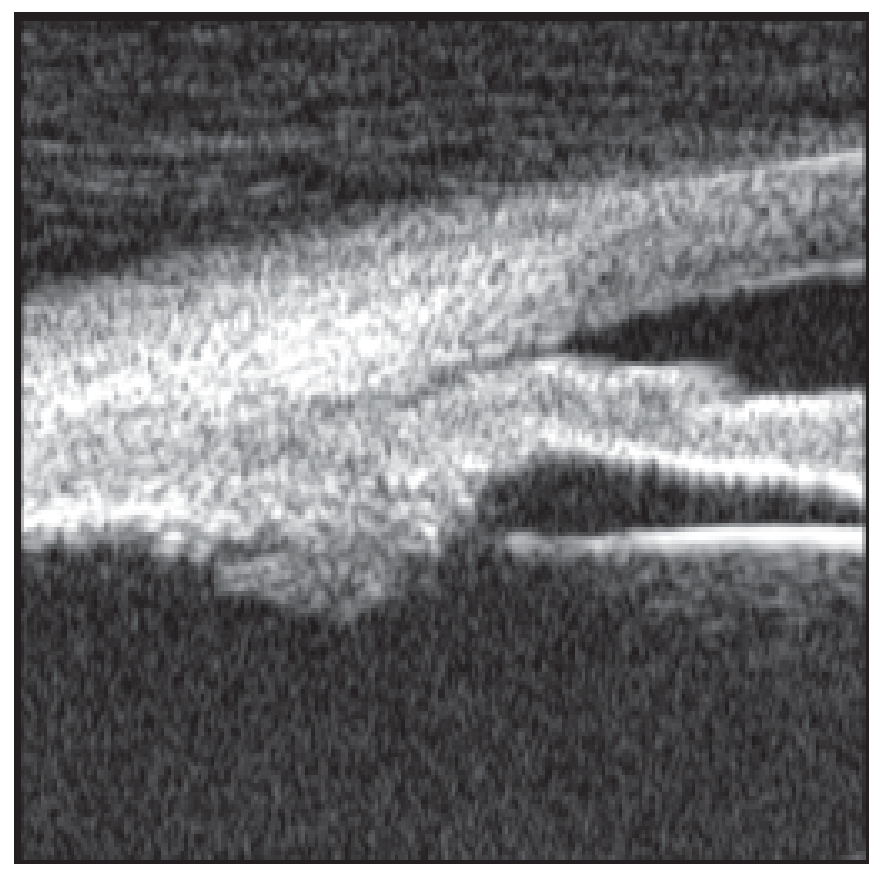

Fig. 4: During Valsalva maneuver (narrowing of the angle)

dysplasia of anterior angle, iris, ciliary body and scleral spur of primary congenital glaucoma. The base of iris is thin, the ciliary body is small, and the anatomic characteristic is not clear. The thickness of iris and size of ciliary body of primary congenital glaucoma are significantly smaller than those of normal control group. The dysplasia of iris and ciliary body may play a relative important role in the pathogenic mechanism of congenital glaucoma.

Another study ${ }^{17}$ evaluating the anterior segment changes in primary infantile glaucoma (PIG) suggests different results. According to the study, no matter the severity of the disease or the age at onset, the most significant characteristics of the diseased eyes are relative positional changes between scleral spur and angle apex. In three-fourth of the eyes, the scleral spur lay in the lateral or posterior-lateral site of the angle apex and in one-fourth of the eyes, the site of the tip of scleral spur was parallel with the iris root insertion. The thickness and length of ciliary processes in the eyes of PIG were greater than that of the normal infantile eyes. The ciliary processes were anteriorly displaced, pulled toward the lens, and part of them got into contact with the iris. The relative positional changes between scleral spur and angle apex in diseased eyes indicate that the poor development of scleral spur and the iris anterior insertion are the basic pathogenetic sequences in PIG.

In cases of cloudy cornea and unknown previous glaucoma surgery, UBM can be used to identify the type and localization of previous surgery in congenital glaucoma, thus assisting surgical planning for subsequent glaucoma management. ${ }^{18-20}$

\section{Determining the Mechanism of Secondary Glaucoma}

\section{Pigment Dispersion Syndrome}

In the pigment dispersion syndrome there is a classical picture on the UBM which include wide opened angle and typical posterior bowing of the peripheral iris (Fig. 5). MendezHernandez $\mathrm{C}^{21}$ et al studied the effect of YAG PI on iris configuration in pigmentary glaucoma. In their study they found that PI rectified the posterior bowing of iris and reduced the number of drugs required to bring down IOP. However, this is only possible in eyes with iridozonular cataract. ${ }^{22}$

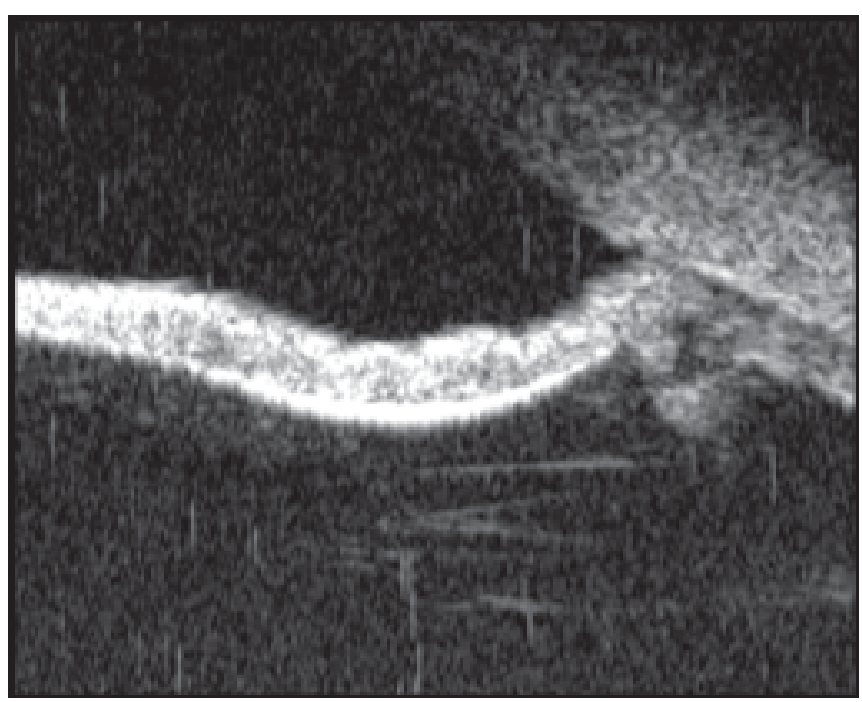

Fig. 5: Concave iris configuration in pigment dispersion syndrome 


\section{Plateau Iris Syndrome}

In plateau iris syndrome, UBM usually reveals an abnormally steep anterior angulation of the peripheral iris, anterior insertion of the iris on to the anterior ciliary body, and retroiridic projection of the ciliary processes (Figs 6 and 7). It can also confirm the "double hump sign" which is normally seen with gonioscopy by use of an indentation UBM, a special technique that imposes mild pressure on peripheral cornea with the skirt of the eyecup. ${ }^{23}$

Garudadri CS et al ${ }^{24}$ evaluated the presence of plateau iris in eyes with primary angle-closure glaucoma (PACG) after laser peripheral iridotomy by gonioscopy and ultrasound biomicroscopy and the pathogenesis of this condition by comparing the UBM parameters of these eyes with those in normal subjects. Among the PACG eyes, after YAG iridectomy, 40 percent had an open-angle (angle-opening distance $>130$ microns) and 60 percent eyes had a narrow angle (angle-opening distance d" 130 microns). A large anteriorly placed ciliary process with a narrow ciliary sulcus was found in 40.9 percent eyes with open-angle, and 66.66 percent eyes with narrow angles. Trabecular ciliary process distance was significantly larger in the eyes with open-angles compared with those with narrow angles. Thus anteriorly directed ciliary processes were seen both in eyes with plateau iris as well as in eyes with PACG that had deep anterior chambers after iridotomy. Plateau iris could be picked up on UBM and found to be common in the study population.

Argon laser iridoplasty is an effective and safe treatment for plateau iris syndrome and may also prove valuable in the treatment of plateau-like iris configuration resulting from iridociliary cysts. ${ }^{25,26}$

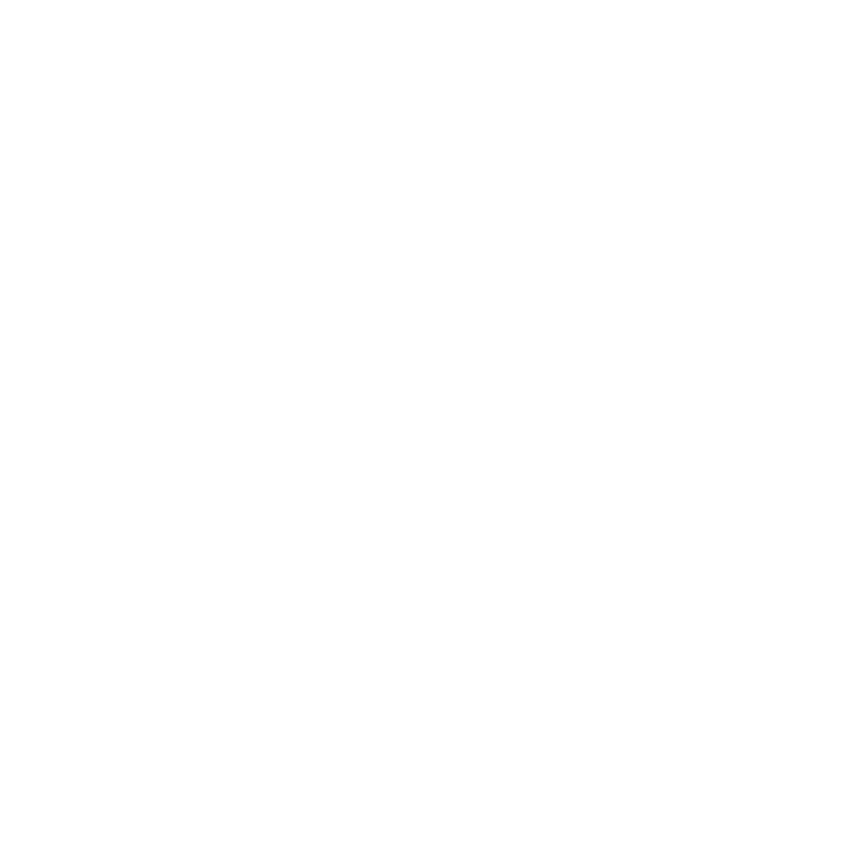

Fig. 6: Plateau iris configuration

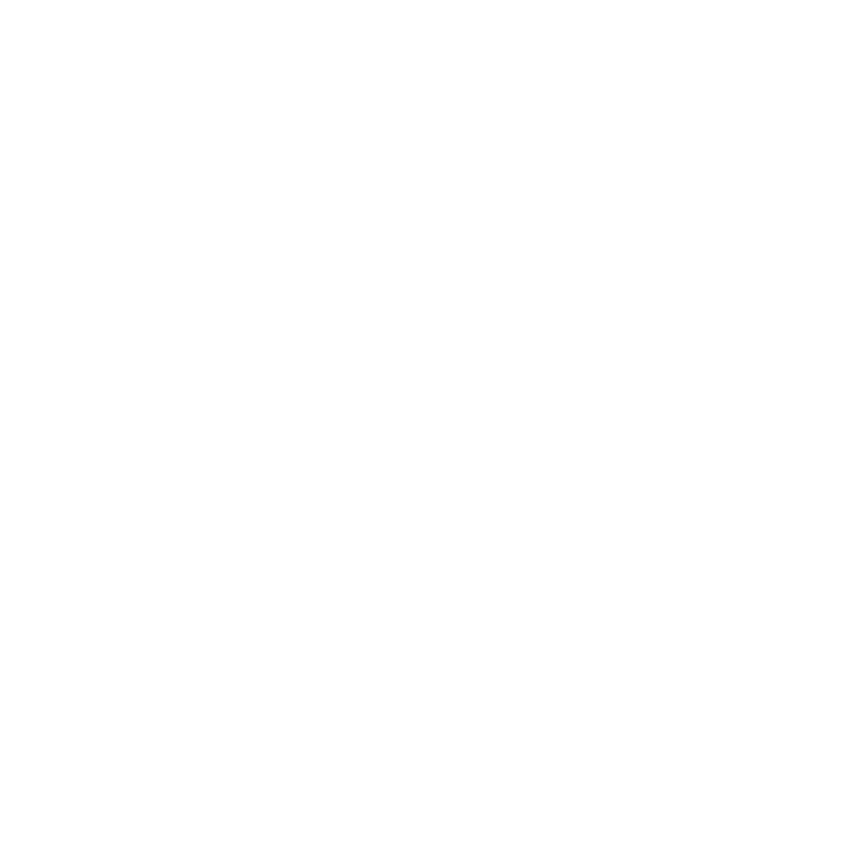

Fig. 7: Prominent occluding angle iris roll

In eyes with peripheral anterior synechiae, UBM can reveal the extent of iridocorneal adhesions, even if the cornea is hazy or opaque (Figs 8 and 9). The UBM has been able to differentiate between primary angle-closure and secondary angle-closure due to processes such as lens swelling and dislocation, massive hemorrhagic retinal detachment pushing the lens and iris anteriorly, and multiple neuroepithelial cysts of the iris and ciliary body.

\section{Aniridia}

Eyes with Aniridia show a rudimentary iris stump and an atrophic ciliary body. Okamoto $\mathrm{F}$ et $\mathrm{al}^{27}$ by ultrasound biomicroscopic imaging demonstrated that there is an iris hypoplasia and ciliary body hypoplasia in aniridia. Anterior

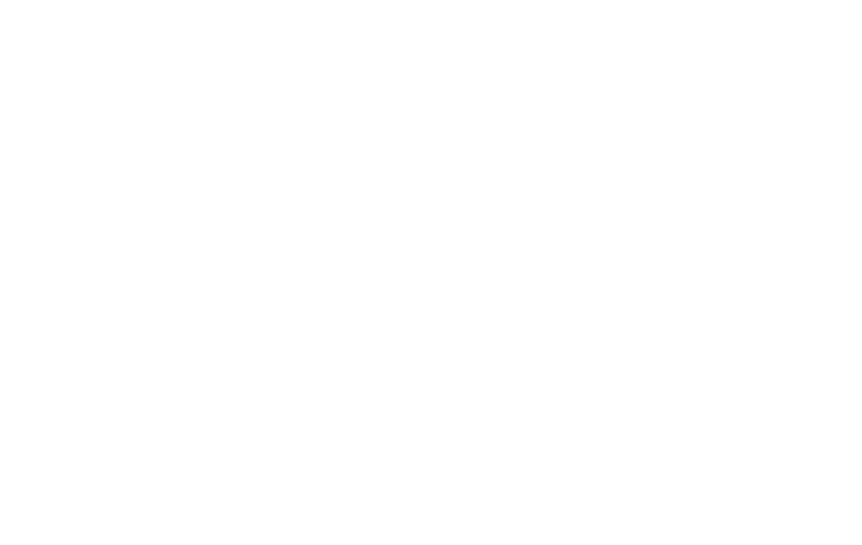

Fig. 8: Peripheral anterior synechiae 


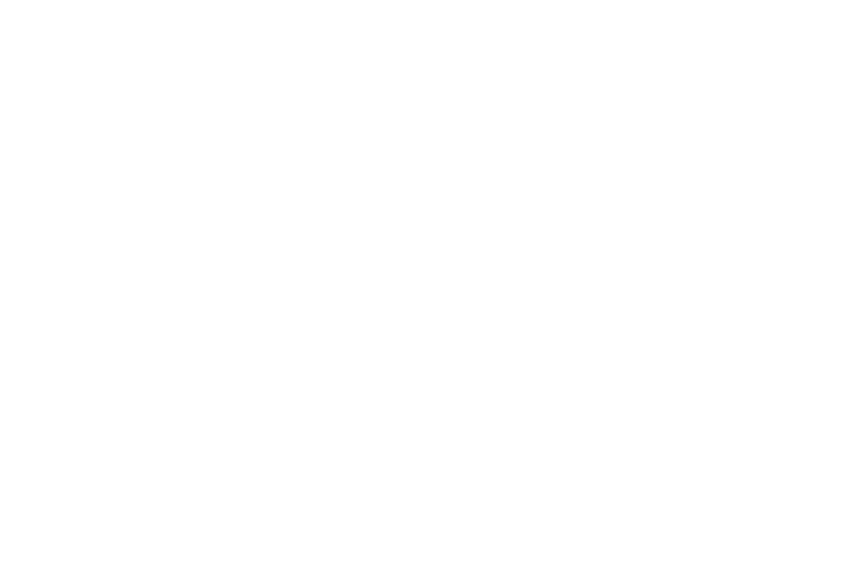

Fig. 9: Iris bombe

inclination of the ciliary process was also found, which was thought to be at least partly responsible for the shallow anterior chamber (Fig. 10).

\section{Sturge-Weber Syndrome}

In Sturge-Weber syndrome associated glaucoma, UBM can show the presence of dilated intrascleral vessels and supraciliary fluid supporting the hypothesis of increased episcleral venous pressure as the cause of elevated intraocular pressure in this condition. $^{28}$

\section{ICE Syndrome}

Zhang $\mathrm{M}$ et $\mathrm{al}^{29}$ compared UBM findings of anterior segment between normal subjects and three clinical types of ICE syndrome: progressive iris atrophy (PIA), Chandler's syndrome (CS), and Cogan-Reese syndrome (CRS). UBM was found to be more effective in detecting peripheral anterior synechiae (PAS) and iris atrophy than slit lamp microscopy and gonioscopy, mainly because of corneal edema in patients with CS. Thus, UBM is an effective method to reveal the anterior segment features and provides a useful tool in the diagnosis of ICE syndrome.

\section{Post-traumatic Glaucoma}

After blunt ocular trauma, UBM can be used to evaluate irisangle abnormalities including angle recession, iridodialysis and cyclodialysis, and to illustrate the presence and extent of blood clots (Figs 11 to 13). Angle recession is characterized on UBM by a posterior displacement of the point of attachment of the iris to the sclera, a widening of the ciliary body face with no disruption of the interface between the sclera and ciliary body. In the acute stage, the post-traumatic recess is usually filled with blood. In contrast, in cyclodialysis, the ciliary body is detached from its normal attachment at the scleral spur. ${ }^{30,31}$ It is particularly useful in the presence of hazy media, hypotony,

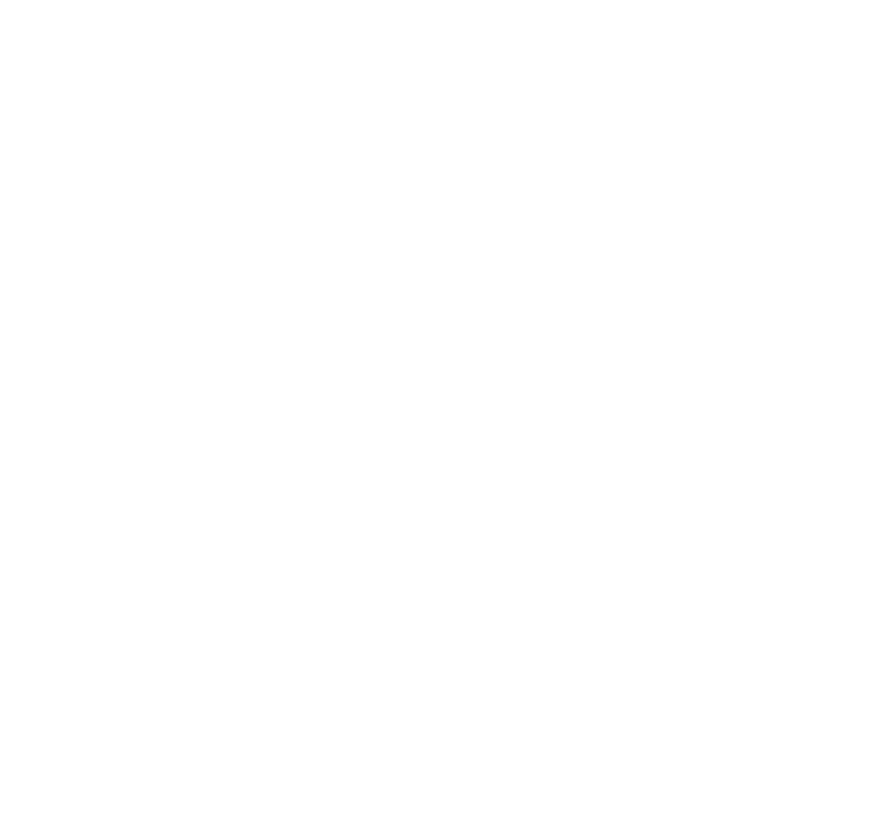

Fig. 10: Aniridia-iris and ciliary hypoplasia

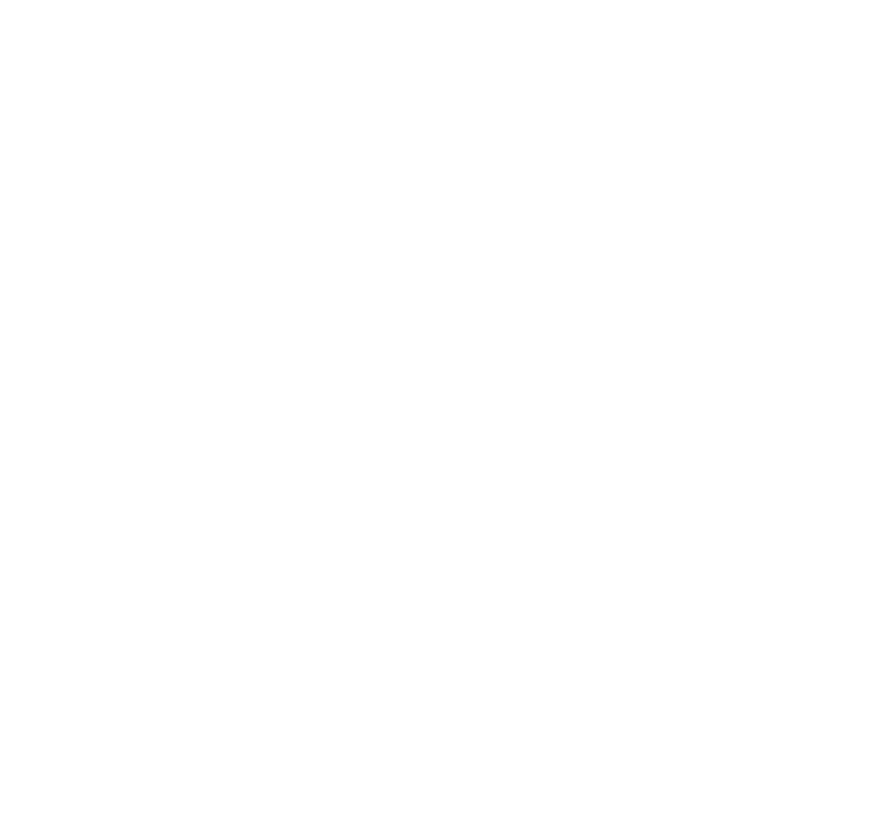

Fig. 11: Angle recession

and/or abnormal anterior segment anatomy. UBM can also identify occult zonular damage in patients with anterior segment trauma. ${ }^{32}$ The ability to diagnose zonular rupture preoperatively is of significant benefit to the ophthalmic surgeon and might reduce the chance of intraoperative complications.

\section{Pseudophakic and Lens-induced Glaucoma}

The UBM can diagnose various types of lens induced glaucomas such as phacomorphic glaucoma and glaucoma due 


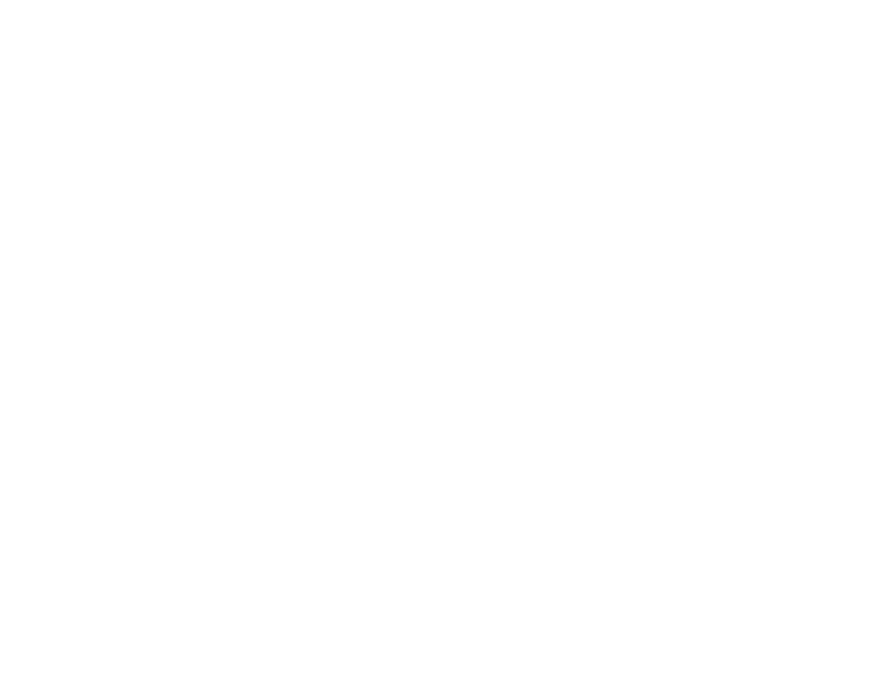

Fig. 12: Iridodialysis

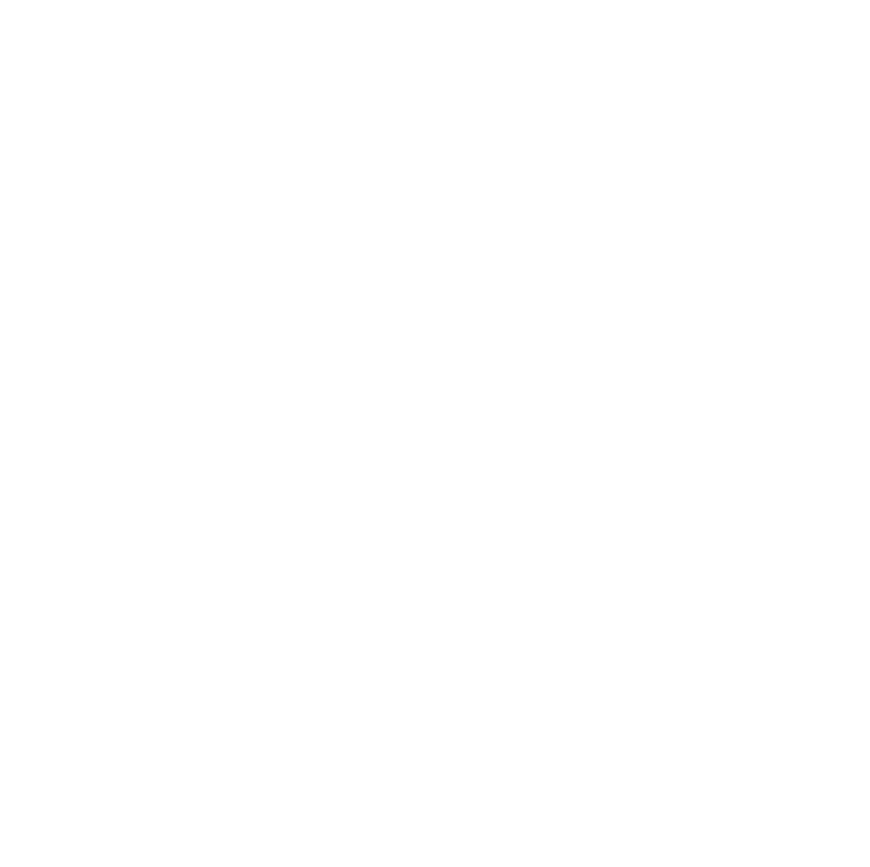

Fig. 13: Small Cyclodialysis with peripheral anterior synechiae obscuring gonioscopic view (Courtesy: Dr Sunil Chaudhary)

to anterior subluxation of lens. It is helpful to know the circumference of intact zonules and the extent of zonular dialysis in pseudoexfoliation syndrome. In case of IOL-induced glaucoma, it can clearly delineate the position of the optic and haptic and is especially helpful in pseudophakic bullous keratopathy cases to determine the cause for glaucoma (Fig. 14).

\section{Secondary Glaucoma after Retinal Surgery}

UBM can be used to evaluate angle changes post vitreoretinal surgery. Genovesi-Ebert et $a l^{33}$ used this technique in the

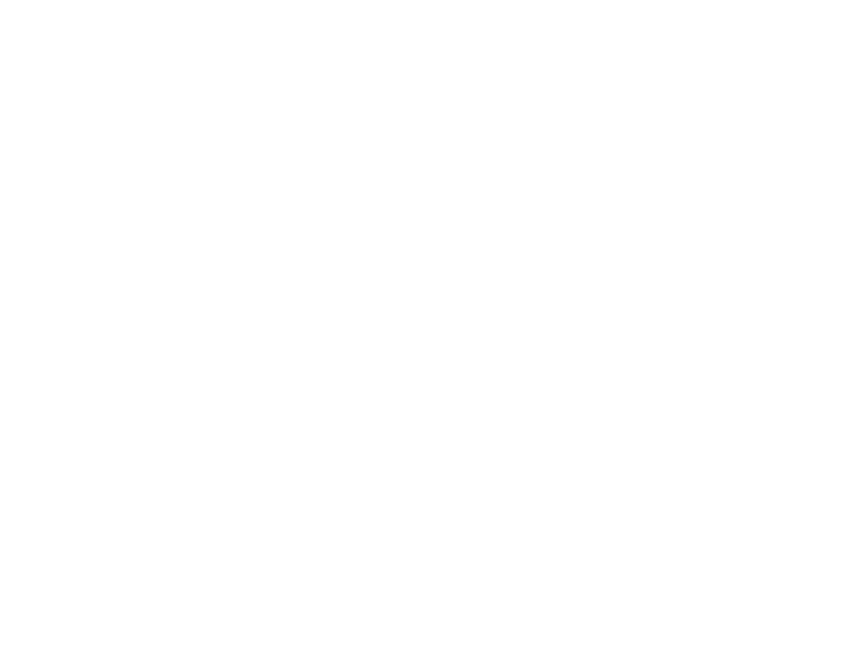

Fig. 14: Secondary angle-closure by $\mathrm{ACIOL}$

assessment of the anterior chamber in patients affected by silicone oil-related glaucoma after vitreoretinal surgery. UBM showed high reflectivity of angular structure, anterior chamber alterations and a fairly atrophic ciliary body. Wei W et $a l^{34}$ studied UBM changes after buckling surgery. The study showed that the anterior chamber angle becomes narrower, the angle-open distance at $500 \mu$ decreases, but the depth of the central anterior chamber has no obvious change. Ciliary body detachment and edema are often found after scleral buckling surgery which may contribute to the angle-closure glaucoma after the surgery.

\section{Diagnosis of Malignant Glaucoma}

Ciliary block or aqueous misdirection presents the greatest diagnostic challenge for the ophthalmologists and the UBM is an important tool in this condition. Imaging shows an extremely shallow anterior chamber, occluded angle, forward rotation of the ciliary body with or without fluid in the suprachoroidal space.

Liu L et $a l^{35}$ studied the onset of malignant glaucoma in living eyes. The mechanism of malignant glaucoma is associated with the abnormal relationship among anterior vitreous, ciliary processes and the lens periphery. Fluid in the supraciliary space makes the ciliary process closer to the lens periphery. It is one of the factors causing ciliolenticular block. The authors concluded that the ultrasound biomicroscopic image is a new better practicable method to diagnose malignant glaucoma during its onset, compared with other methods at present used in the clinical work. It is much more valuable to differentiate the pupillary block glaucoma from malignant glaucoma.

Sometimes malignant glaucoma is suspected in cases of secondary glaucoma like iridocyclitis, lens subluxation resulting from trauma and glaucoma filtration surgery. ${ }^{36}$ In the cases of lens subluxation, the main characteristic was the increase of the 
distance between the lens and the ciliary process at the site of subluxation and forward movement of the lens. In iridocyclitis, anterior and posterior synechiae were the main characteristics, while in glaucoma filtration surgery there are two main characteristics. One was decreased distance between the ciliary process and the equator of lens, and the other was occlusion of the inner ostium of glaucoma filtration surgery or peripheral iridectomy. Thus UBM has an important value in the diagnosis of secondary pupillary block glaucoma and the differentiation between it and malignant glaucoma. Whether the posterior chamber exists or not is the main differentiating point between the pupillary block glaucoma and the malignant glaucoma.

\section{Evaluation of Cysts and Tumors causing Angle-closure}

Cysts and solid tumors of the anterior segment can be imaged in great detail with UBM. ${ }^{37,38}$ This technology can be used to determine the internal character of a lesion (solid or cystic), to ascertain whether the lesion involves the anterior ciliary body or is restricted to the iris, and to measure the full extent of the lesion. UBM can reveal whether the lesion involves only partial thickness or full thickness of the stroma and can thereby aid in surgical planning. It allows measurement of the lesion's thickness and determination of the presence or absence or intraocular invasion. It also confirms the presence, character, and extent of ciliary body tumors and often reveals the route of access of the tumor to the surface by way of a scleral emissary canal. With the UBM one can follow up the progression or regression of the tumor with exact documentation of the dimensions of the tumor (Figs 15 and 16). Cystic lesions due to parasitic infestation can also be detected ${ }^{39}$ with UBM, which may not be obvious on clinical examination.

\section{EVALUATION OF GLAUCOMA THERAPY}

Apart from the diagnostic applications UBM is also useful in planning, assessing and following-up the treatment in glaucoma, especially laser and surgical management. This is especially useful in monitoring glaucoma filtration surgery and determining the cause for any complications associated with the procedure.

\section{Determining Patency and Effect of Laser Iridotomy}

After Nd-YAG laser iridotomy for angle-closure, UBM can show whether the iridotomy is partial thickness or full thickness and whether the plane of curvature of the peripheral iris has changed, compared with the pretreatment findings ${ }^{40}$ (Figs 17 and 18).

In case of pigment dispersion syndrome, laser iridotomy (LI) eliminates the pressure gradient between anterior and posterior chamber and relieves reverse pupillary block. The UBM can clearly show the flattened iris after iridotomy. ${ }^{41}$ Any

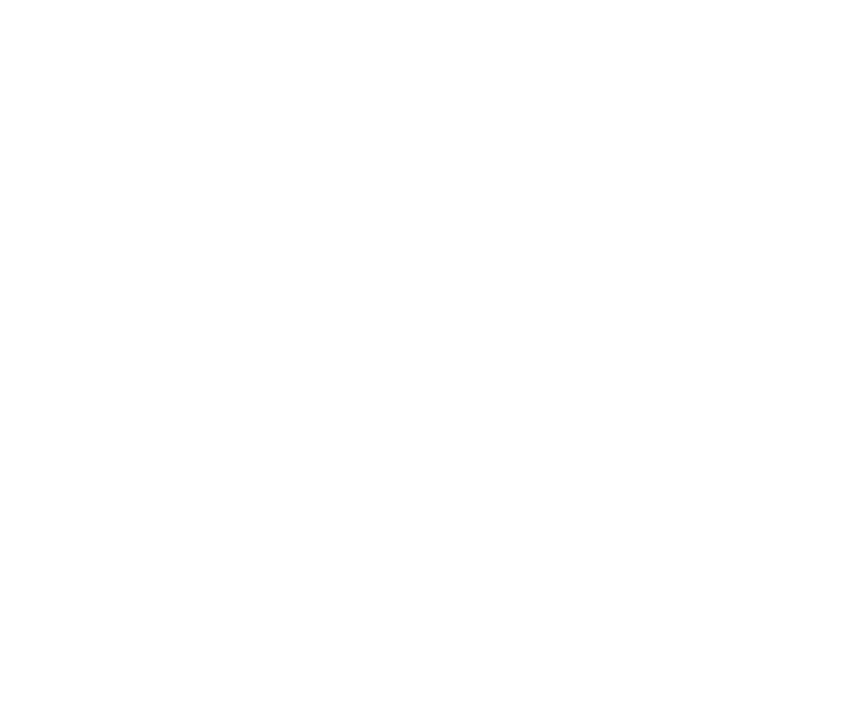

Fig. 15: Iris cysts

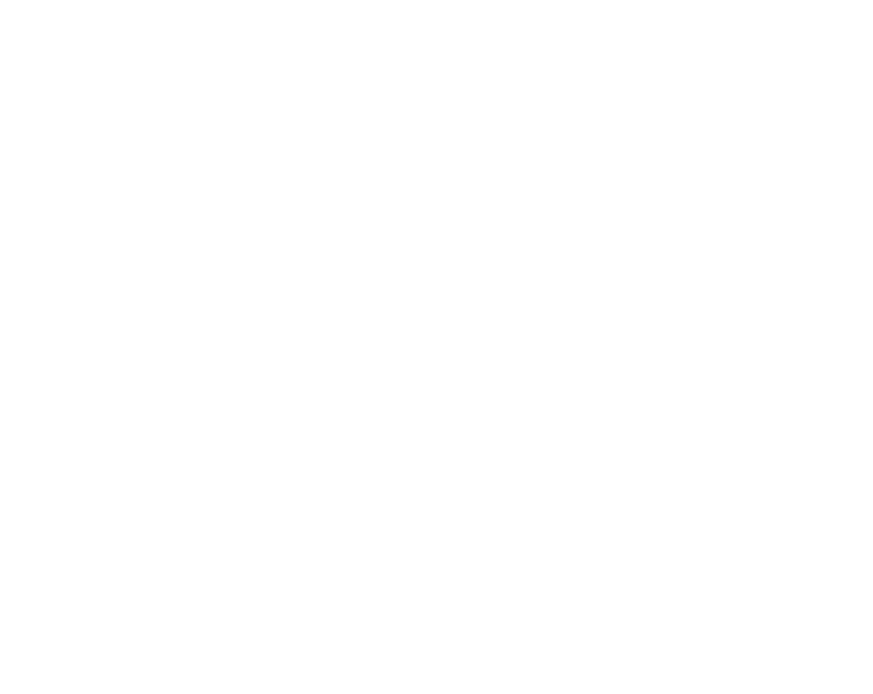

Fig. 16: Ciliary body tumor

damage to the lens caused by the laser can also be highlighted on the UBM. Subclinical choroidal effusion observed by UBM frequently occurs after LI and is reported to be more frequent after Argon -LI as compared to YAG-LI. ${ }^{42}$

Dada $\mathrm{T}$ et $a l^{43}$ studied changes in anterior segment morphology after laser peripheral iridotomy (LPI) in primary angle-closure (PAC) and primary angle-closure glaucoma (PACG) using ultrasound biomicroscopy (UBM). They found that LPI leads to a widening of the anterior chamber angle and a deepening of the anterior chamber in eyes with PAC; however, it does not significantly change any anterior segment parameters in eyes with PACG. Kaushik S et al ${ }^{44}$ added that LPI significantly widened the anterior chamber angle in the quadrant with LPI and the quadrant farthest away, in patients of CACG with established glaucomatous damage. 

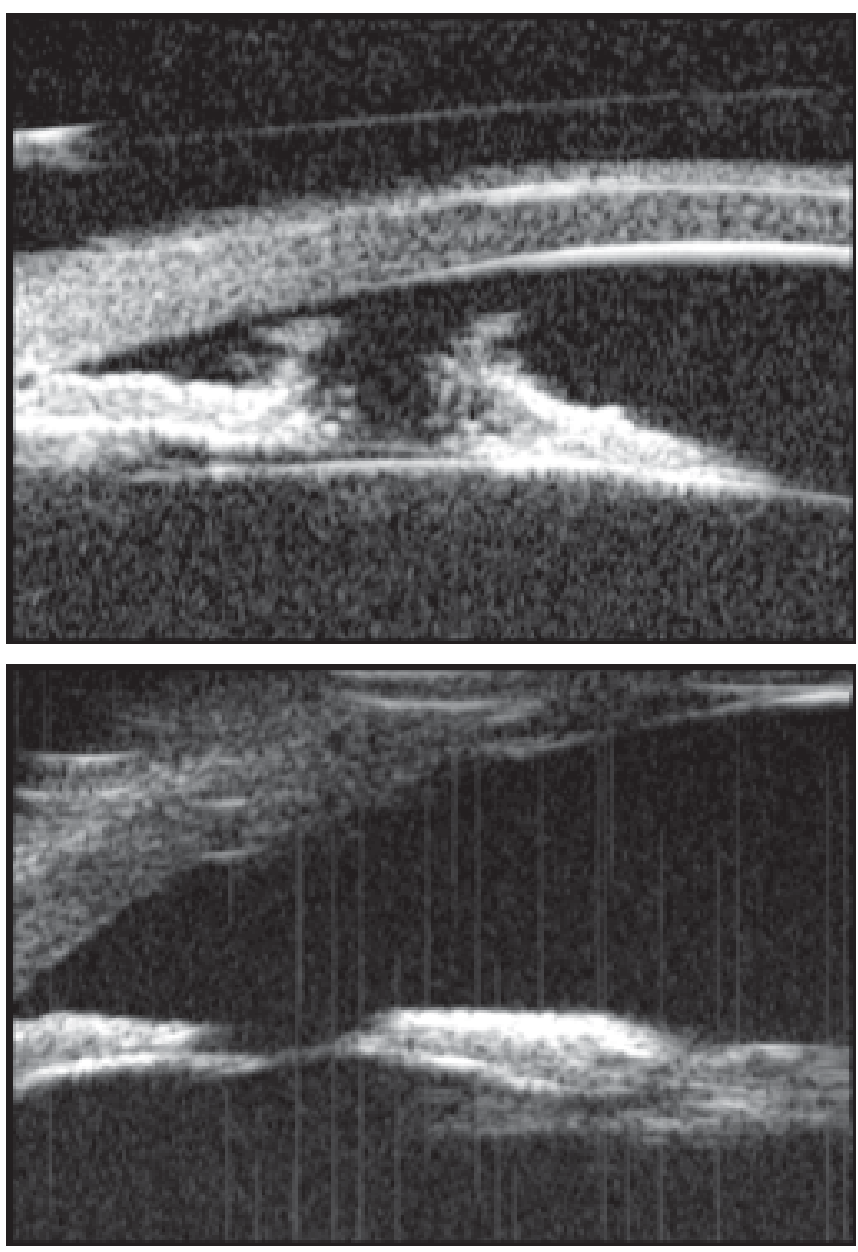

Figs 17 and 18: Nd-YAG iridotomy

Residual angle-closure after iridotomy is common, especially in eyes with primary angle-closure and poorly controlled IOP or glaucomatous optic neuropathy. Nonaka et $a l^{45}$ studied residual angle-closure after iridotomy and found it to be present in 38.6 percent of eyes. This was confirmed functionally by the darkroom prone position test and morphologically by UBM. They found that cataract surgery was effective in completely resolving the residual angle-closure after iridotomy and lower the IOP.

\section{Determining Functional Status of a Filtering Surgery}

After trabeculectomy, UBM can show whether the sclerostomy aperture is patent or blocked internally, whether the peripheral iridectomy is patent and whether the filtering bleb is flat, shallow, or deep (Figs 19 and 20).

After glaucoma drainage device surgery, UBM can show the position of the tip of the tube and whether its orifice is open or plugged.

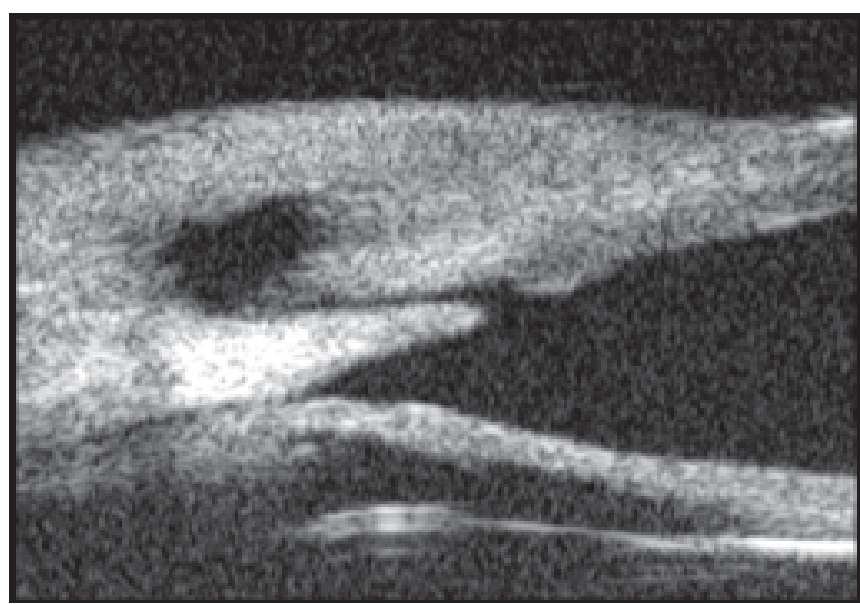

Fig. 19: Functional bleb post-trabeculectomy

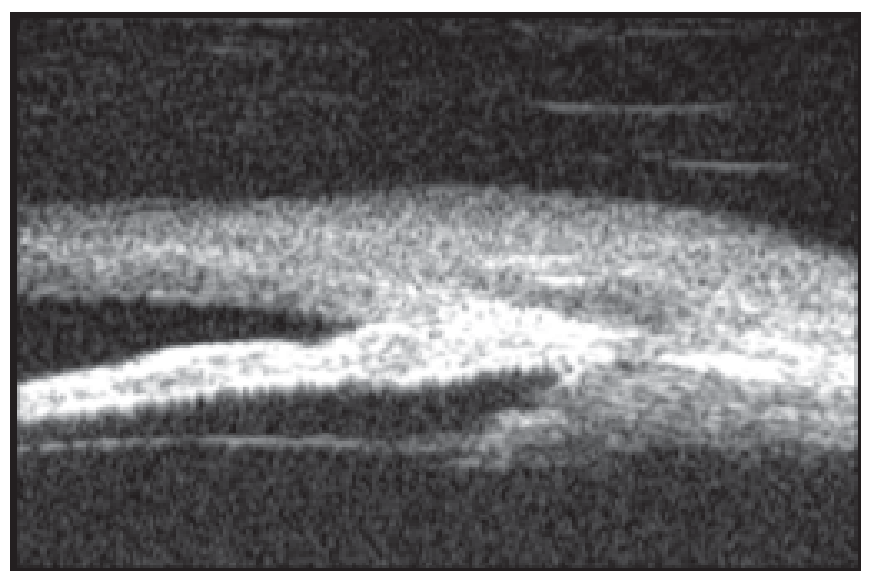

Fig. 20: Failing filtering bleb with increased echogenicity due to subconjunctival fibrosis

The grading of the bleb is done according to intrableb reflectivity, visibility of route under the scleral flap, formation of cavernous fluid filled space, and bleb height. Following four grades have been described:

- Low reflective (L)

- High reflective $(\mathrm{H})$

- Encapsulated (E)

- Flat (F).

Eyes with good IOP control mainly have 'L' type blebs, these have low to moderate intrableb reflectivity, visible intrascleral route and higher intrableb height. Flat and encapsulated blebs generally denote a surgical failure.

The bleb morphology after the use of adjunctive agents like $\mathrm{C}_{3} \mathrm{~F}_{8}$ can also be studied on the UBM (Fig. 21).

Avitabile $\mathrm{T}$ et $a l^{46}$ studied the correlation of bleb morphology on UBM and functional status with effect of laser suturelysis. They found a statistically significant correlation between the UBM classification of function and the IOP control level. Both well-functioning and failed trabeculectomies could 


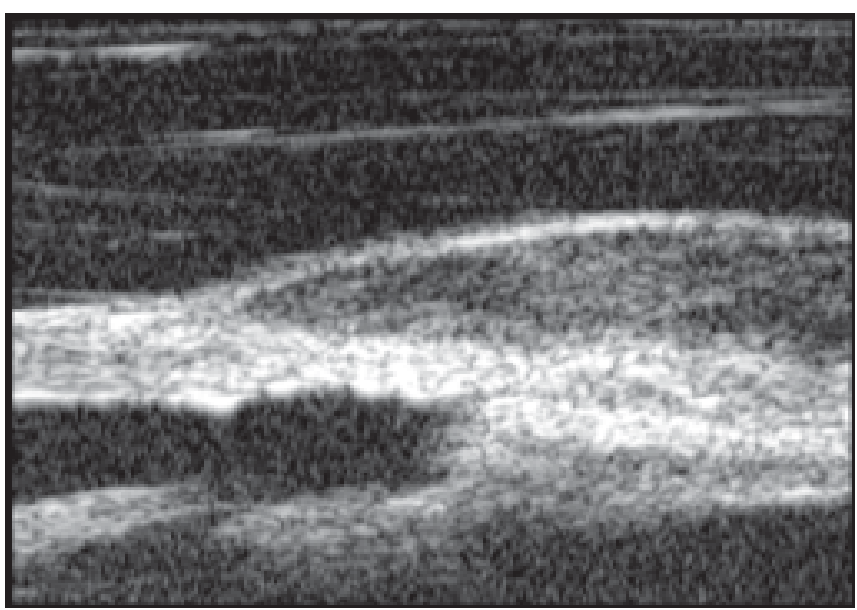

Fig. 21: Bleb morphology after subconjunctival $C_{3} F_{8}$ injection

be identified by UBM. The UBM images of eyes with good IOP control are characterized by better visibility of the route under the scleral flap and a low reflectivity inside the bleb. Thus, UBM can be a useful method to study and explain the mechanisms of filtering structures and, together with IOP control, to evaluate the bleb function. It can identify the site of failureinternal ostium, episcleral or subconjunctival.

\section{Nonpenetrating Deep Sclerectomy}

The UBM may be used in eyes which have undergone nonpenetrating deep sclerectomy (NPDS) to evaluate the functional status of the surgery. It can evaluate the thickness and demonstrate a non-perforated continuous trabeculoDescemet's membrane. In patients undergoing deep sclerectomy, UBM examination after long-term follow-up shows the presence of an intrascleral space (lake) and a filtering bleb. ${ }^{47}$ Collagen implants used to augment deep sclerectomy can also be visualized using this technology. ${ }^{48} \mathrm{~A}$ grading of bleb similar to the trabeculectomy bleb has also been used for NPDS blebs . Information provided by UBM is useful and assists in understanding the mechanism of action of deep sclerectomy.

Wang Y et $a l^{49}$ studied causes of failure of NPDS with SKGeL (a hyaluronic acid biological gel) implant and possible treatment options. The examination of UBM showed that the filtering bleb disappeared and there was a liquid chamber under the superficial scleral flap in every failure case. The scarring at conjunctiva-Tenon's capsule-superficial scleral flap interface was the most important cause of NPTS with SKGeL implant failure.

Park $\mathrm{M}$ et $a l^{50}$ studied ultrasound biomicroscopy of intrascleral lake after viscocanalostomy and cataract surgery. They found combined viscocanalostomy and cataract surgery lowered IOP without bleb formation. Postoperatively, the size of the lake and IOP decreased, suggesting parallel reduction of the two. The lake was undetected ultrasonographically in onethird of the cases, up to 1 year postoperatively.

\section{Other Surgeries}

Ultrasound biomicroscopy of the anterior chamber angle could demonstrate restoration of an open-anterior chamber angle after goniosynechialysis. ${ }^{51}$ An experimental study on UBM-guided chamber angle surgery was done by Dietlein TS et al. ${ }^{52}$ Mechanical goniopuncture or Er:YAG laser trabecular ablation was performed without operating microscope or gonioscopy, but with real-life ultrasound biomicroscopy monitoring with a $50 \mathrm{MHz}$ transducer. It was observed that the instruments could be clearly visualized within the chamber angle and disturbing artifacts were only minimal when using mechanically fixed instruments in slow motion. Topographic localization, tissue contact, and penetration depth of the instruments entering the sclera were well illustrated as far as the technical resolution limits of UBM would allow. UBM-guided surgery may soon become a feasible option.

The UBM is also useful in diagnosing the presence and cause of occlusion of aqueous drainage devices. ${ }^{53}$ (Fig. 22). In eyes with post penetrating keratoplasty glaucoma, the UBM is helpful in identifying degree of iridocorneal apposition, measuring the corneal thickness, evaluating the lens/IOL status and establishing the cause for raised IOP. It also aids the corneal surgeon in planning regrafting in such cases.

Pereira FA et al ${ }^{54}$ studied effect of cataract surgery on angle structures. After phacoemulsification and foldable IOL implantation, UBM revealed that the iris diaphragm shifted backward, deepening the anterior chamber by approximately 850 microns and widening its angle by approximately 10 degrees. These findings may be of clinical significance in eyes with angleclosure glaucoma or with occludable angles.

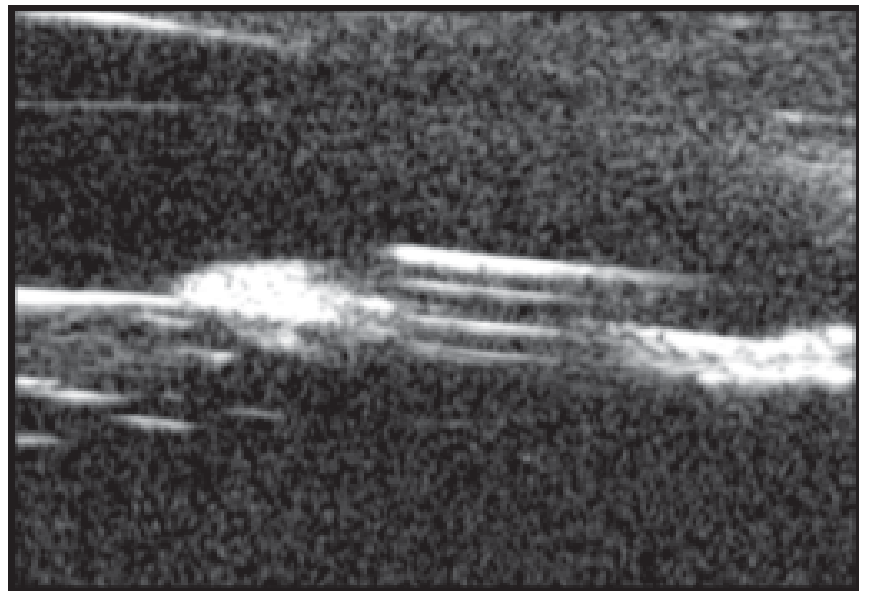

Fig. 22: Patent tube of an aqueous drainage device 


\section{Evaluation of Postoperative Complications after Trabeculectomy}

After any type of glaucoma filtering surgery, UBM can be used to detect and evaluate the extent of postoperative complications such as cilio-choroidal effusion and cyclodialysis (Fig. 23). In ciliochoroidal effusion, UBM shows the ciliary body to be edematous and separated from the sclera by a sonolucent collection of supraciliary fluid. Many ciliochoroidal effusions that are too limited in extent to be detectable by indirect ophthalmoscopy and slit-lamp biomicroscopy can be imaged by UBM. A study done by Sugimoto $\mathrm{K}$ et al ${ }^{55}$ revealed that suprachoroidal fluid (SCF) was present more frequently at an early stage after trabeculectomy and results indicate that the presence of SCF is related to the initial low IOP recorded after trabeculectomy, while its disappearance is associated with elevation of IOP.

Information about changes in the trabeculectomy ostium and adjacent structures related to flattening of the anterior chamber in the early postoperative period can also be documented on the UBM.

Grigera $\mathrm{D}$ et $\mathrm{al}^{56}$ studied the pathophysiology of flat anterior chamber without bleb leak. Ring-shaped effusions were detected on UBM even in cases in which conventional ultrasonography showed no positive results.

The UBM can be used for exact measurements of the anterior chamber dimensions, angulation of the iris, measurements of surgical fistulas, to determine adequacy of drainage postsurgery and document over time the resolution of ciliochoroidal effusion.

\section{COMPARISON OF UBM WITH ANTERIOR SEGMENT OCT}

The UBM and anterior segment OCT can both be used in evaluation of angle in glaucoma. Advantages of OCT include noncontact technique, easy to learn, can be used to assess refractive surgeries on cornea. Advantages of UBM include ability to visualize ciliary body, pars plana and zonules. Dada et $a l^{57}$ compared anterior segment parameters using quantitative imaging by anterior segment OCT and UBM and found comparable results. Radhakrishnan $\mathrm{S}$ et $\mathrm{al}^{58}$ also found similar results. Hence both the modalities are useful in aid to glaucoma evaluation with few advantages and disadvantages of each modality.

\section{CONCLUSION}

Ultrasound biomicroscopy has revolutionized the evaluation of the anterior segment of the eye. The structures surrounding the posterior chamber which were difficult to examine clinically now are being imaged and assessed in detail. The qualitative and quantitative evaluation using this technology has

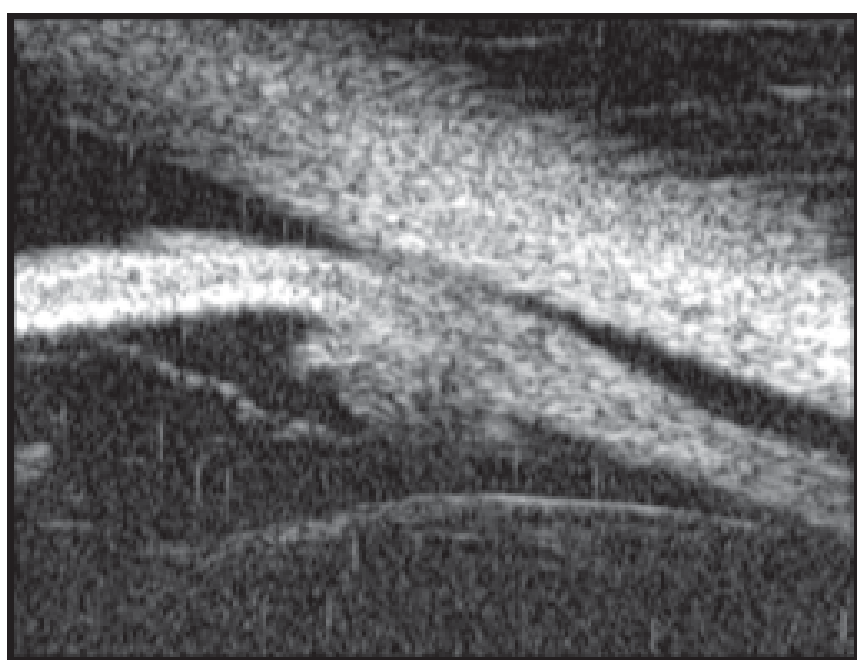

Fig. 23: Ciliochoroidal effusion

contributed to our understanding of the pathophysiology of angle-closure glaucoma, pigmentary glaucoma, secondary glaucoma and a variety of other anterior segment disorders. The use of this technology gives an excellent view of the pathology occurring in the anterior and posterior chambers of the eye and allows objective documentation of the anterior chamber angle and the ciliary body, thereby, providing a clear insight into the cause for aqueous obstruction. It also aids in prognostication of a glaucoma case and in establishing the cause for failure of filtering surgery.

\section{REFERENCES}

1. Pavlin CJ, Harasiewicz K, Foster FS. Ultrasound biomicroscopy of anterior segment structures in normal and glaucomatous eyes. Am J Ophthalmol 1992;113:381-9.

2. Pavlin CJ, Sherar BA, Foster FS. Subsurface ultrasound microscopic imaging of the intact eye. Ophthalmology 1990;97:244-50.

3. Pavlin CJ, Harasiewicz K, Sherar BA, Foster FS. Clinical use of ultrasound biomicroscopy. Ophthalmology 1991;98:287-95.

4. Kapetansky FM. A new water bath for ultrasonic biomicroscopy. Ophthalmic Surg Lasers 1997;28(7):605-6.

5. Esaki K, Ishikawa H, Leibmann JM, et al. A technique for performing ultrasound biomicroscopy in the sitting and prone positions. Ophthalmic Surg Lasers 2000;31(2):166-9.

6. Ishikawa $\mathrm{H}$, Schuman JS. Anterior segment imaging: ultrasound biomiscroscopy. Ophthalmol Clin N Am 2004;17:7-20.

7. Marchini G, Pagliarusco A, Toscano A, et al. Ultrasound biomicroscopic and conventional ultrasonographic study of ocular dimentions in primary angle-closure glaucoma. Ophthalmology 1998;105:2091-8.

8. Sihota R, Dada T, Gupta R, et al. Ultrasound biomicroscopy in the subtypes of primary angle-closure glaucoma. J Glaucoma 2005;14(5):387-91. 
9. Nonaka A, Iwawaki T, Kikuchi M, et al. Quantitative evaluation of iris convexity in primary angle-closure. Am J Ophthalmol 2007;143(4):695-7.

10. Wang N, Lai M, Cheng X, Ye T. Ultrasound biomicroscopic darkroom provocative test. Zhonghua Yan Ke Za Zhi 1998;34(3):183-6,12.

11. Sano R, Kurokawa T, Kurimoto Y, et al. Comparison between the anterior chamber configuration in the supine position and that in the prone position in patients with narrow angle. Nippon Ganka Gakkai Zasshi 2001;105(6):388-93.

12. Ishikawa H, Esaki K, Leibmann JM, et al. Ultrasound biomicroscopy darkroom provocative testing: a quantitative method for estimating anterior chamber angle width. Jpn J Ophthalmol 1999;43(6):526-34.

13. Matsunga K, Ito K, Esaki K, et al. Evaluation and comparison of indentation ultrasound biomicroscopy gonioscopy in relative pupillary block, peripheral anterior synechia, and plateau iris configuration. J Glaucoma 2004;13(6):516-9.

14. Sihota R, Dada T, Gupta V, et al. Narrowing of the anterior chamber angle during Valsalva maneuver: a possible mechanism for angle-closure. Euro J Ophtalmol (accepted for publication).

15. Huang W, Peng D, Chen X. Study on the dynamic examination of anterior chamber angle by ultrasound biomicroscopy. Yan Ke Xue Bao 1998;14(4):204-6.

16. Avitabile T, Russo V, Uva MG, Marino A, Castiglione F, Reibaldi A. Ultrasound-biomicroscopic evaluation of filtering blebs after laser suture lysis trabeculectomy. Ophthalmologica 1998;212(suppl) 1:17-21.

17. Zhu X, Li Z, Lin D, Tang X, Yang W, Hu S, Wang L. A study of anterior segment structures in primary infantile glaucoma eyes by ultrasound biomicroscopy Zhonghua Yan Ke Za Zhi 1999;35(4):300-4.

18. Dietlein TS, Engels BF, Jacobi PC, Krieglstein GK. Ultrasound biomicroscopic patterns after glaucoma surgery in congenital glaucoma. Ophthalmology 2000;107(6):1200-5.

19. Engels BF, Dietlein TS, Jacobi PC, Krieglstein GK. Ultrasound biomicroscopy diagnosis of congenital glaucoma. Klin Monatsbl Augenheilkd 1999;215(6):338-41.

20. Azuara-Blanco A, Spaeth GL, Araujo SV, Augsburger JJ, Katz LJ, Calhoun JH, Wilson RP. Ultrasound biomicroscopy in infantile glaucoma. Ophthalmology 1997;104(7):1116-9.

21. Mendez-Hernandez C, Garcia-Feijoo J, Cuina-Sardina R, et al. Ultrasound biomicroscopy in pigmentary glaucoma.Arch Soc Esp Oftalmol 2003;78(3):137-42.

22. Pillunat LE, Bohm A, Fuisting B, et al. Ultrasound biomicroscopy in pigmentary glaucoma. Ophthalmologe 2000;97(4):268-71.

23. Chiou AG, Mermoud A, Underdahl JP, et al. An Ultrasound biomicroscopic study of eyes after deep sclerectomy with collagen implant Ophthalmology 1998;105:746-50.

24. Garudadri CS, Chelerkar V, Nutheti R. An ultrasound biomicroscopic study of the anterior segment in Indian eyes with primary angle-closure glaucoma. J Glaucoma 2002;11(6):502-7.

25. Crowston JG, Medeiros FA, Mosaed S, Weinreb RN. Argon laser iridoplasty in the treatment of plateau-like iris configuration as result of numerous ciliary body cysts. Am J Ophthalmol 2005;139(2):381-3.

26. Ouazzani BT, Berkani M, Ecoffet M, Lachkar Y. Argon laser iridoplasty in the treatment of angle-closure glaucoma with plateau iris syndrome. J Fr Ophtalmol 2006;29(6):625-8.

27. Okamoto F, Nakano S, Okamoto C, et al. Ultrasound biomicroscopic findings in aniridia. Am J Ophthalmol 2004;137(5):858-62.

28. Kranemann CF, Pavlin CJ, Trope GE. Ultrasound biomicroscopy in Sturge-Weber-associated glaucoma. Am J Ophthalmol 1998;125(1):119-21

29. Zhang M, Chen J, Liang L, Laties AM, Liu Z. Ultrasound biomicroscopy of Chinese eyes with iridocorneal endothelial syndrome. Br J Ophthalmol 2006;90(1):64-9.

30. Berinstein DM, Gentile RC, Sidoti PA, et al. Ultrasound biomicroscopy in anterior ocular trauma. Ophthalmic Surg Lasers 1997;28:201-7.

31. Park M, Kondo T. Ultrasound biomicroscopic findings in a case of cyclodialysis. Ophthalmologica 1998;212:194-7.

32. McWhae JA, Crichton AC, Rinke M. Ultrasound biomicroscopy for the assessment of zonules after ocular trauma. Ophthalmology 2003;110(7):1340-3.

33. Genovesi-Ebert F, Rizzo S, Chiellini S, Gabbriellini G, Laddaga F, Nardi M. Ultrasound biomicroscopy in the assessment of secondary glaucoma after vitreoretinal surgery and silicone oil injection. Ophthalmologica 1998;212 (suppl) 1:4-5.

34. Wei W, Yang W, Chen Z, Zhu X, Wang J. A study on ocular anterior segment structure after scleral buckling surgery for retinal detachment. Zhonghua Yan Ke Za Zhi 1999;35(4):309-11,17.

35. Liu L, Wang T, Li Z. Studies of mechanism of malignant glaucoma using ultrasound biomicroscope. Zhonghua Yan Ke Za Zhi 1998;34(3):178-82,10.

36. Wang T, Liu L, Li Z, Zhang S. Ultrasound biomicroscopic examination of secondary pupillary block glaucoma. Zhonghua Yan Ke Za Zhi 2000;36(6):413-5,27.

37. Katsimpris JM, Petropoulos IK, Sunaric-Megevand G. Ultrasound biomicroscopy evaluation of angle-closure in a patient with multiple and bilateral iridociliary cysts. Klin Monatsbl Augenheilkd. 2007;224(4):324-7.

38. Matsui N, Kamao T, Azumi A. Case of metastatic intraocular malignant lymphoma with neovascular glaucoma. Nippon Ganka Gakkai Zasshi 2005;109(7):434-9.

39. Bhende M, Biswas J, Gopal L. Ultrasound biomicroscopy in the diagnosis and management of intraocular gnathostomiasis. Am J Ophthalmol 2005;140(1):140-2.

40. Gazzard G, Friedman DS, Devereux JG, Chew P, Seah SK. A prospective ultrasound biomicroscopy evaluation of changes in anterior segment morphology after laser iridotomy in Asian eyes. Ophthalmology. 2003;110(3):630-8.

41. Breingan PJ, Esaki K, Ishikawa $\mathrm{H}$, et al. Iridolenticular contact decreases following laser iridotomy for pigment dispersion syndrome. Arch Ophthalmol 1999; 117:325-8.

42. Sakai H, Ishikawa H, Shinzato M, Nakamura Y, Sakai M, Sawaguchi S. Prevalence of ciliochoroidal effusion after prophylactic laser iridotomy. Am J Ophthalmol 2003;136(3):537-8. 
43. Dada T, Mohan S, Sihota R, Gupta R, Gupta V, Pandey RM. Comparison of ultrasound biomicroscopic parameters after laser iridotomy in eyes with primary angle-closure and primary angleclosure glaucoma. Eye 2006; (Epub ahead of print).

44. Kaushik S, Kumar S, Jain R, Bansal R, Pandav SS, Gupta A. Ultrasound biomicroscopic quantification of the change in anterior chamber angle following laser peripheral iridotomy in early chronic primary angle-closure glaucoma. Eye 2006; (Epub ahead of print).

45. Nonaka A, Kondo T, Kikuchi M, Yamashiro K, Fujihara M, Iwawaki T, Yamamoto K, Kurimoto Y. Cataract surgery for residual angle-closure after peripheral laser iridotomy. Ophthalmology 2005;112(6):974-9.

46. Avitabile T, Russo V, Uva MG, Marino A, Castiglione F, Reibaldi A. Ultrasound-biomicroscopic evaluation of filtering blebs after laser suture lysis trabeculectomy. Ophthalmologica 1998;212 (suppl)1:17-21.

47. Khairy HA, Atta HR, Green FD, et al. Ultrasound biomicroscopy in deep sclerectomy. Eye 2005; 19(5):555-60.

48. Contreras I, Noval S, Munoz-Negrete FJ. Ultrasound biomicroscopy in deep sclerectomy with a new acrylic implant. Arch Soc Esp Oftalmol 2006;81(8):445-50.

49. Wang Y, Sun XH, Meng FR, Wang JJ. The failure causes of nonpenetrating trabecular surgery and reoperation. Zhongua Yan Ke Za Zhi 2003:39(2):87-90 (Chinese).

50. Park M, Tanito M, Nishikawa M, Chihara E. Ultrasound biomicroscopy of intrascleral lake after viscocanalostomy and cataract surgery. J Glaucoma 2004;13(6):472-8.
51. Canlas OA, Ishikawa H, Leibmann JM, et al. Ultrasound biomicroscopy before and after goniosynechialysis. Am J Ophthalmol 2001;132 (4):570-1.

52. Dietlein TS, Engels BF, Jacobi PC, Krieglstein GK. UBM-guided chamber angle surgery for glaucoma management: an experimental study. Eye 2003;17(3):340-5.

53. Carrillo MM, Trope GE, Pavlin C, et al. Use of ultrasound biomicroscopy to diagnose Ahmed valve obstruction by iris. Can J Ophthalmol 2005;40(4):499-501.

54. Pereira FA, Cronemberger S. Ultrasound biomicroscopic study of anterior segment changes after phacoemulsification and foldable intraocular lens implantation. Ophthalmology 2003;110(9):1799806.

55. Sugimoto K, Ito K, Esaki K, Miyamura M, Sasoh M, Uji Y. Supraciliochoroidal fluid at an early stage after trabeculectomy. Jpn J Ophthalmol 2002;46(5):548-52.

56. Grigera D, Moreno C, Fava O, Girado SG. Ultrasound biomicroscopy in eyes with anterior chamber flattening after trabeculectomy. Can J Ophthalmol 2002;37(1):27-32; discussion 32-3.

57. Dada T, Sihota R, Gadia R, Aggarwal A, Mandal S, Gupta V. Comparison of anterior segment optical coherence tomography and ultrasound biomicroscopy for assessment of the anterior segment. J Cataract Refract Surg 2007;33(5):837-40.

58. Radhakrishnan S, Goldsmith J, Huang D, et al. Comparison of optical coherence tomography and ultrasound biomicroscopy for detection of narrow anterior chamber angles. Arch Ophthalmol 2005;123(8):1053-9. 